\title{
Study on the Integrating Strategy of Market Resources in a University Community by Micro-Blog Platform
}

\author{
Peng CHEN \\ Economics and Management School \\ Jiujiang University \\ Jiujiang, China \\ jjucp@qq.com
}

\author{
Xiaoting Zheng \\ Electronic Commerce School \\ Jiujiang University \\ Jiujiang, China \\ zxting888@qq.com
}

\begin{abstract}
This paper analyzes market structure around the university community, consumption structure of college teachers and students and analyzes the possibility of combining market resources around the university communities by means of microblog. Moreover, micro-blog can provide technology, marketing, management and service functions for entrepreneurs. In the end, entrepreneurs are suggested to provide life convenience for college teachers, students as well as community residents nearby in the following four areas: information enquiry, online mealordering, preferential promotion and tourism promotion.
\end{abstract}

Keywords-micro-blog; university community; market resource; integrating strategy

\section{INTRODUCTION}

A university community is a main place for college teachers and students to live, study and communicate. The range of community is about 500 meters around the university, and about 5-minutes-walk area. The market within the scope is to provide various services for teachers and college students' activities, e.g. working, studying, communicating, entertaining and others. There are many ways of promotions and services in traditional market, most of which are static and passive. With the development of Internet and WEB technology, especially the developing of many new mobile Internet applications, there are more and more choices and opportunities for integrating market resources around university community. This paper discusses on how to integrate university community market resources by microblog platform.

\section{CurRent SituAtion of MARKET Resources in A UNIVERSITY COMMUNITY}

\section{A. Structure of Market Resources}

\section{1) Catering}

The catering industry is the main market resources of the university community, which is provided by hotels holding classmate party, inns offering a takeaway service, and some fast food shop etc. Nowadays, college students are getting more and more demands for food. They don't just ask to be full, but more is to ask for a comfortable, healthy diet. In the university community, the food industry is very profitable, but the competition is very fierce.

\section{2) Entertainment}

There is a variety of entertainment places in a university community, including KTV, bar, Internet cafes, cinemas, etc, which offer a wide range of commodities and services. There is a saying, "each university has a fallen Street”. In this street, students spend most of their spare time and pocket money.

\section{3) Accommodation}

The accommodation resource includes high and middle level hotels together with some cost-effective inns. Generally speaking, college students do not often live in the hotel, except for entertaining friends or family members.

4) Study

In and around universities, there are many kinds of training classes for certificate examinations, and also many bookstores selling study references. These training institutions and bookstores together with online bookstores provide extracurricular knowledge for students.

In addition, there are many travel agencies, supermarkets, grocery stores and cloth-stores in university community.

\section{B. Consumption Structure of Teachers and Students}

In a survey about consumption structure and status, 1000 college students from freshmen to seniors received the questionnaire. There are 500 questionnaires handed out to boys and girls respectively, and 980 are handed in. Then we find the highest proportion of college students is diet, up to $38.8 \%$. The second is shopping, about $22.8 \%$. The third is transportation and communication, about $16.3 \%$. The next ones are study, entertainment, love, about $11.5 \%$, 3.5\% and $4.1 \%$ respectively. the last is social intercourse and other expense, up to $2.2 \%$ and $0.8 \%$ respectively. In short, the consumption structure of college students shows the characteristics of diversity and plenteousness(Table I).

The consumption time of college students focuses on weekends. Some students go out of campus and watch movies, go to supermarket, chat in bars and sing songs, and the others' consumption mainly is taking away food. 
In order to be closer to work, college teachers usually live in or around campus, so their consumption in university community mainly focuses on diet, household commodities and clothes. Other expenses of teachers such as entrainment or shopping are out of university community.

TABLE I. CONSUMPTION STRUCTURE OF STUDENTS (\%)

\begin{tabular}{|c|c|c|c|c|c|c|}
\hline $\begin{array}{l}\text { Sort } \\
\text { Students }\end{array}$ & Diet & $\begin{array}{l}\text { Shop- } \\
\text { ping }\end{array}$ & $\begin{array}{l}\text { Transport } \\
\text { ation \& } \\
\text { Communi } \\
\text { cation }\end{array}$ & Study & $\begin{array}{l}\text { Entertain } \\
\text { ment \& } \\
\text { Love }\end{array}$ & $\begin{array}{l}\text { Social } \\
\text { Intercourse } \\
\text { \& Others }\end{array}$ \\
\hline Average & 38.8 & 22.8 & 16.3 & 11.5 & 7.6 & 3.0 \\
\hline Freshman & 43.2 & 20.4 & 13.1 & 15.2 & 5.0 & 3.1 \\
\hline Sophomore & 40.5 & 21.5 & 14.6 & 13.1 & 6.5 & 3.8 \\
\hline Junior & 37.3 & 23.8 & 16.3 & 10.5 & 9.2 & 2.9 \\
\hline Senior & 34.3 & 25.3 & 21.2 & 7.2 & 9.7 & 2.3 \\
\hline
\end{tabular}

\section{FEASIBILITY ANALYSIS OF INTEGRATING UNIVERSITY} COMMUNITY RESOURCES BY MiCRO-BLOG PLATFORM

\section{A. The Huge Number of Micro-blog Users}

Micro-blog is a blog of one sentence, and a broadcast platform to share brief real-time information by listening to each others' account[1]. With its constant development, micro-blog shows strong vitality and improving functions.

Micro-blog is not only to transmit information, but also to develop an unlimited platform. According to official statistics by Sina Weibo Corporation, by the end of December, 2015, the average monthly number of Weibo active users (MAUs) is about 236 million, indicating an increase of 34\%. The average daily number of active users is 106 millon, indicating an increase of 32\%[2]. It only took several years that Sina Weibo earned a value of billions of "golden eggs" for Sina Corporation. Moreover, Weibo platform shows the following features: the low cost of micro-blog marketing, the precise target clients, the convenient channels, the high speed and wide range of information transmission.

\section{B. The Advantages of Micro-blog Integration Platform}

Micro-blog takes advantage of the most convenient channel in marketing - the network. Compared with traditional marketing, such as one-to-one marketing, experiential marketing, relationship marketing, micro-blog has the feature of spreading in high speed and large scale. Compared to other similar network marketing, micro-blog marketing is much closer to the majority of mobile-phone users. If a micro-blog, that is, a message within 140 words, is issued, and then forwarded among fans, it will be similar to a virus-spreading mode. Its sense of real-time, rapidness and extensiveness will be stronger than any other media.

Micro-blog also creates a new mode. Namely, users can gather friends of the same hobby or the same label to form a micro-blog group. All the topics concerned are collected in the group, so that the friends can communicate more easily. We can utilize the group to get together college teachers and students of the same label, spread by forwarding comments, or, we can make advertisement at the first stage, in order that some people know about the platform, and then more and more college teachers and students know about it by its virusspreading marketing mode, which can save the advertising cost in the next stages.

This micro-blog platform serves in and out of campus, and maybe greatly expands the market. Obviously, it is a mode of mutual benefit for services providers and consumers.

\section{MiCRO-BLOG ENTREPRENEURIAL FUnCTIONS ANALYSIS}

\section{A. Technology Functions}

As a social platform, most features of Micro-blog are designed for social functions. In terms of entrepreneurship, these functions play a very large role in marketing. For example, the broadcast and forwarding functions can describe and promote their products and services for specific groups, so that more people know about their products and services and reach an advertising group effect. Besides, Micro-blog also helps to allow customers to know the latest changes of the product in the first time and maximizes marketing efficiency. After receiving the promotion of products and services, clients can use Micro-blog's subscribing and collecting functions, which help to develop potential customers. Thanks to technology functions, Micro-blog marketing is much more deep and broad than traditional marketing.

In the 140 characters restrictions of new media content, operators need ingenious idea of micro-blog marketing ideas, so that contents will not make main page Information boring. Hard-advertising nature must be published with special caution, because this information has caused consumers' fatigue, exclusion and resentment. Compared to other media carriers, Micro-blog can make more use of animation, text, video, audio and other media contents, which is more attractive to the target consumers.

\section{B. Marketing Functions}

Micro-blog can be an excellent marketing platform, where there are extensive market resources. Compared with traditional marketing methods, Micro-blog marketing is much more effective and it can save time and expenses[3]. Entrepreneurs can locate their customer and implement promotion of products or services more accurately and quickly according to the different needs of different client groups.

When companies use micro-blog platform to carry out marketing activities, they must be sure to pay attention to the positive interaction with users. Micro-blog is a two-way communication platform; companies should not only serve as a positive message sender, but also as an information recipient. They should listen carefully to the customers' needs and feelings, value customers' opinions, answers to questions about corporation and products. Through the exchange, companies can understand the instant needs of clients, so as to grasp of market dynamics[4]. 


\section{Management Functions}

Micro-blog has a powerful information management and customer management functions. For examples, operators can use grouping functions to analyze and classify their customers, which contribute to customer relationship management. In addition, there are different kinds of micro-blog data analysis applications, such as Micro-data, Pipi Time Machine, Microblog keyword analyzing tools, batch management tools, etc.[5] Some of these applications are officially provided; others are developed by third-party.

\section{Service Functions}

On the micro-blog platform, operators can use the "private letter" for service exchanges with customers in the first time. In the process, the specific needs of different customers can be satisfied $r$ respectively. After finishing the whole service, customers can use micro-blog's comment function to make requests and recommendations, which helps to improve the quality of products and services. All there information exchange can be public or private just depend on the operators, which is helpful to increase customer loyalty and create a new brand.

\section{THE STRATEGY OF INTEGRATING UNIVERSITY COMMUNITY BY MICRO-BLOG}

Each university community has a variety of catering industry, entertainment industry, and garment-selling industry. The industries are mainly consumed by college teachers and students, so the scale is not very large. Businesses often just rely on the traditional off-line sales, ignoring the network marketing platform. Because the distribution is much dispersed, many businesses sometimes appear insufficient resources, or resources idle, which result in low utilization rate of resources.

In order to allocate and make use of these resources much better, a platform based on micro-blog can be built. The platform will be divided into four columns. And the market resources will be further integrated. In details, all the restaurant information is integrated into a column for enquiry; all taking-out information is integrated into a column for online delivery; all the preferential information is integrated into a column to provide preferential services; all travel information is integrated into a column for reference.

\section{A. Information Enquiry}

In the platform, the information service corporation can integrate several industries together around the universities, such as catering industry, service industry, and entertainment industry. And then it provides accommodation, catering location, price enquiry etc. In the past, students do not know which hotel nearby the universities is fully-occupied, whether the room type is OK for them. The same thing may appear on cinema. The information service corporation can offer information inquiry, book tickets and select seats online on this platform, which is not only good for teachers and students to save time, but also for resources to be used effectively.

\section{B. Online Meal-ordering}

For college students, to have three meals every day is one of the most important things. The information service corporation can collect the names, addresses, telephone numbers, introduction and recommended dishes of takingaway restaurants by learning the mode of "Are you hungry" website. Then consumers can comment by the unique function of micro-blog, including taste, environment, service (which are marked by grade), per capita consumption, the favorite taking-away dishes etc. Students can order taking-away meals online directly, make payment online or pay cash on delivery. The function does not only save time for students, but decrease the cost and increase the profit for restaurant owners.

\section{Preferential Promotion}

For most consumers, the biggest attract is discount and promotion activities of supermarkets and other consuming sites. If propagated by traditional advertisement, these activities will show great limitations, which is not favorable for students to know more details about that in the relatively closed environment. Consequently, we can integrate all the discount and promotion information around university by micro-blog platform. There are two advantages. One is that the students can get to know the preference information in the fastest time by micro-blog's transmission function. The other is that the information service corporation integrates all the preference information for reference and offer services to students much better.

\section{Tourism}

Tourism has already become an indispensable part of college students in daily life[6]. At the same time, there are a large number of travel agencies and tourism information in universities. College students have a strong rejection to unfamiliar things. Usually, they are generally reluctant to consult the travel agencies initiatively. But they are ready to obtain all the information needed online, because it is very simple, fast, convenient and efficient for them. For example, how many are there travel agencies nearby? Which routes can be offered by agencies? What are their prices? All these questions can be solved by micro-blog platform easily. The information service corporation may cooperate with travel agencies in universities, and then set up a column of "travel" following the "information enquiry", which is favorable to integrate travel information into "travel” column.

\section{SUMMARY}

As a new method of information interaction in 21th century, micro-blog narrows the distance and forms close relationship among people. In university community, microblog platform creates a new consumption mode, and shows great prospects. In one hand, college teachers and students will enjoy better services form merchants on micro-blog platform. In the other hand, the market resources in or around universities will be used more efficiently so as to facilitate life, travel, consumption of the community residents. 


\section{REFERENCES}

[1] Peng Wen. "On Marketing of micro-blog," Chinese E-commerce. pp.13-14, June, 2010. (In Chinese)

[2] Weibo Corporation, "Weibo Reports Fourth Quarter and Fiscal Year 2015 Financial Results”,March 02,2016

[3] Liu Jiandi,”On the marketing strategy of micro-blog,” Finance Teaching and Research, Vol.139, pp.43-45,May, 2011 (In Chinese)

[4] JIN Zhongkun, "Research on the Effects of Micro-blog Marketing on Consumers'Willingness to Buy, “China Business and Market,pp.3744,Dec.2015(In Chinese)

[5] Xu Ye, "Microblog---Innovation Applications Changing the World," Forum on Science and Technology in China,pp.23-27, Aug. 2012 (In Chinese)

[6] Jia Yunfeng, Zhao Jiajun. "micro-blog leads tourism marketing into quick speed era, “ China Tourism News. May 4 ${ }^{\text {th }}, 2010$. (In Chinese) 